International Review of Research in Open and Distributed Learning Volume 18, Number 4

June - 2017

\title{
Cultivating Textbook Alternatives From the Ground Up: One Public University's Sustainable Model for Open and Alternative Educational Resource Proliferation
}
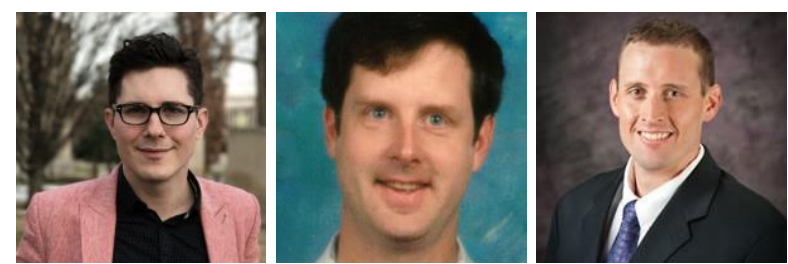

Jonathan Lashley ${ }^{1}$, Rebel Cummings-Sauls², Andrew B. Bennett ${ }^{3}$, and Brian L. Lindshield ${ }^{4}$

${ }^{1}$ Boise State University, 2,3,4 Kansas State University

\begin{abstract}
This note from the field reviews the sustainability of an institution-wide program for adopting and adapting open and alternative educational resources (OAER) at Kansas State University (K-State). Developed in consult of open textbook initiatives at other institutions and modified around the needs and expectations of K-State students and faculty, this initiative proposes a sustainable means of incentivizing faculty participation via institutional support, encouraging the creation and maintenance of OAER through recurring funding, promoting innovative realizations of "educational resources" beyond traditional textbooks, and rallying faculty participation in adopting increasingly open textbook alternatives. The history and resulting structure of the initiative raise certain recommendations for how public universities may sustainably offset student textbook costs while also empowering the pedagogies of educators via a more methodical approach to adopting open materials.
\end{abstract}

Keywords: higher education, sustainable initiatives, open educational resources, OER, Open/Alternative Resources, OAER, Kansas State University, K-State

\section{Introduction}

Textbooks are expensive. The Bureau of Labor and Statistics (2016) has documented an 88\% increase in textbook prices over the last 10 years. During that same period (2006-2016), college tuition and fees as well as housing (excluding board) have risen by $63 \%$ and $51 \%$, respectively. Though the cost of a post- 
secondary education has risen across the board, the rise in textbook prices for consumers has continued to break away disproportionately from other college-related expenses (Bureau of Labor and Statistics, 2016). When the high cost of required course materials is compounded with tuition and other fees, the burden shouldered by students in general and those from lower socioeconomic backgrounds, in particular, becomes apparent (Paulsen \& St. John, 2002). Delays in college enrollment, decisions to take fewer classes each term, shared resources, or even the refusal to purchase required texts are a few of the consequences that students face when commercial textbooks serve as the primary educational resources in college classrooms (Buczynski, 2007; Provasnik \& Planty, 2008). Under this instructional model-one that pairs curriculum with mandatory commercial resources-a system of winners and losers is inevitably established: some students can afford to fully access course content and others cannot.

\section{The Call for Open Educational Resources}

To address this imbalance, some educators have looked to the concept of open educational resources (OER) as a possible solution. Pitched as a strategy for sharing educational materials in developing countries, the United Nations Educational, Scientific, and Cultural Organization (UNESCO) defined OER as openly licensed learning materials that could be accessed, used, and modified for noncommercial purposes by way of open licensing and digital networks (UNESCO, 2002). Since then, OER have proliferated internationally as a means of combatting the costs of textbooks and other educational materials (Bliss, Hilton, Wiley, \& Thanos, 2013; Everard \& Pierre, 2014; Hilton, Robinson, Wiley, \& Ackerman, 2014). Much of this growth may be associated with two necessary components of OER that differentiate it from traditional, commercial educational resources:

1. The "open" of OER promotes unfettered access to courses, materials, media, texts, tests, software, and tools that assist teaching, learning, and researching (William and Flora Hewlett Foundation, 2013).

2. The open licensing of these materials grants users rights to retain, reuse, revise, remix, and redistribute OER in ways that are unavailable under traditional copyright (Wiley, Bliss \& McEwen, 2014).

Taken together, these characteristics define OER broadly in terms of form and function. If interpreted akin to what Wiley (2000) calls learning objects-digital resources that may be reused to support learning-OER may entice instructors by allowing them independence in customizing course materials to fit learning contexts. In the case of open textbooks, the genre's familiar formats organize content that may be augmented to better fit an instructor's needs. The reality, however, is that few instructors choose to remix or revise the material of open textbooks (Hilton, Lutz, \& Wiley, 2012).

Simply, the open textbooks that are already available seem good enough for many instructors (Allen \& Seaman, 2016). Factoring in the time, effort, and skill it might take an instructor to customize or update open textbooks, as well as the limited incentives and support structures available for each instructor to do such things at their institutions, there is little wonder that OER adoption has often been characterized as merely replacing a traditional textbook with an open, pre-existing alternative. When institutional support is scarce, opportunities to revise and remix open content may seem non-essential for many instructors. 
When an individual's urge to revise and remix is suppressed, the promise of OER seems under-realized. Elaborating on the significance of this observation are the five barriers which Andrade et al. (2011) suggest that individuals have confronted when using OER: (1) lack of institutional support, (2) lack of technological tools for sharing and adapting resources, (3) lack of skills and time of users, (4) lack of quality or fitness of OER, and (5) personal issues such as lack of trust and time (Andrade et al., 2011, p. 159). Notably, the first four of the five issues above are related to a lack of larger support mechanisms-opportunities and services that an institution and its staff/teechnology could reasonably facilitate. The fifth may be considered a cultural concern that, while not directly resolvable by institutional resources, may be combated through one's participation in a community that is supported by a university and rich with peers who value the practices enabled through OER. In addition to the barriers isolated by Andrade et al., many instructors have struggled to find the most effective OER on their own (McKerlich, Ives, \& McGreal, 2013). Where institutions might employ teams of employees to vet information and educational resources, arguably few educators have the time and incentive to thoroughly cull through all available course materials. Institutional support of instructors as they adopt OER seems necessary in facing these challenges, that is if OER is to sustain and thrive.

\section{Models of OER Adoption and Consumption}

An instructor's act of sustainably adopting and adapting OER, especially open textbooks, is often too technical or unwieldy without the support-financial or otherwise-of a greater institution. Because a sustainable OER initiative is "unlikely to be reducible to a single metric or calculation" (Downes, 2007, p. 34 ), the promise of institutional support must financially and administratively ensure that instructors have access to necessary training, software, content, publishing, and networking resources. And so Downes (2007) recommends that to instigate sustainable OER adoption, an initiative must account for the volunteers, incentives, communities, partnerships, co-production, sharing, distribution, and management that come with OER use:

The use of a learning resource, through adaptation and repurposing, becomes the production of another resource. Though there is a steady stream of new resources input into the network by volunteers, this represents, not the result of an OER sustainability project, but the beginning of it.

(Downes, 2007, p. 41)

As individual instructors experiment and customize open course materials, alternative texts and interventions may, and arguably should, begin to take shape as use instigates modification that sponsors new use and sharing. A sustainable, institutional model for OER adoption is thus assuredly resourced by an institution and creatively sustained by the efforts of those within academic communities.

Flat World Knowledge (FWK), touted just such a sustainable OER business plan when it was formed in 2007 (Hilton \& Wiley, 2011). Under its initial vision, FWK would offer editorial and design support to expert authors and publish the resulting digital textbooks for free online under Creative Commons licensing. Operating revenue would be generated via the production and sale of printed and audio versions of these texts, as well as supplemental learning objects. During FWK's beta, the majority of students (59\%) made a purchase through FWK averaging $\$ 28.20$ (Hilton \& Wiley, 2010). Not only was this expense significantly smaller than the price of standard course materials, but also it suggested that FWK's "freemium" model to 
OER proliferation could be sustainable as long as for-profit products remained popular add-ons to free textbooks (Hilton \& Wiley, 2010). During FWK's first year of public operation, however, Hilton and Wiley (2011) noted that the number of students purchasing printed textbooks alone fell from $39 \%$ in the beta to 29\%. Furthermore, where 59\% of students purchased products directly from FWK during the beta, only $16 \%$ did so in the following year. While bookstore sales of FWK products replaced some of the purchases made through FWK in that first year, only $34 \%$ of students purchased FWK products altogether. Compare that percentage (34\%) with the percentage of students who purchased products in the beta (59\%), and the critical threat to FWK's model arose from the prospect that institutional revenue and therefore instructor support would suffer "if an increasing number of students become comfortable with the free version of its textbooks and choose not to purchase printed books or ancillary materials" (Hilton \& Wiley, 2011, para. 19). By 2013, FWK conceded to this reality by discontinuing its distribution of no-cost digital textbooks in favor of only publishing and selling low-cost products (Howard, 2012; Lederman, 2012). By not being able to ensure and sustain the investments of students-a necessary part of any academic community-the FYK model could not remain "open."

A number of universities have sought to support the work of their educators as OER authors. In these cases, financial and technical support have been provided to authors in exchange for the public promotion of a university's affiliated image and credibility (Downes, 2007). Indeed, for long-standing institutional models like MIT's OpenCourseWare project, the school's brand and the prominence of its OER are mutually tied to public perception of the partnership. The vitality of the Massachusetts Institute of Technology (MIT) OpenCourseWare project may be linked to its: (1) being recognizable the world over, (2) working in addition to standard MIT offerings, (3) broadly defining OER from content to courses, and (4) reflecting well on the university's mission and operations (Friesen, 2009). As changes in student recruitment, retention, and success become empirically connected to the successful dissemination of institution-sponsored OER over time, an institutional model for OER has potential to gradually and culturally innovate the "practice, community, and policy" of an individual, an academic group, and an institution toward "lofty but laudable goals" (Friesen, 2009). That is, of course, if the participation of an academic community-students and faculty alike- is not only ensured but also enabled to proliferate.

The sustainability of such a model would rely on a cycle in which instructors leverage the administrative resources of an institution in order to produce educational resources that students value enough to use, which generates data that encourages faculty to update resources and validates the administration's continued support. Participation and support must be ensured at all levels-students, faculty, and administrators-for this model to prove self-sustaining. Because an OER initiative relies on creation and sharing, it may be appropriate to consider how the stakeholders of such a model comprise a "participatory culture," which is defined by its (1) lower barriers of creative expression and social engagement, (2) greater support of individuals creating and sharing their work, (3) providing access to informal mentorship and guidance, and (4) members feeling that their contributions matter to others (Jenkins, Purushotma, Clinton, Weigel, \& Robinson, 2006). As a creative force, instructors are at the heart of such a culture as they create and share resources, mentor one another, and work for the betterment of their peers and students with little resistance. Administrative participation is just as critical to the germination of a participatory culture of OER adoption since it is administrators who must remove barriers, engage and educate other university leaders, support the work of faculty and students, and inevitably reconcile the value of the initiative as part 
the greater strategic plan of the university. Finally, it is necessary that students have a means of directly supporting and offering feedback to their instructors about educational resources, engaging one another about the financial burdens associated with their educations, and ultimately recognizing that their voices are being heard and considered by faculty and administrators. When factored in broadly among the contexts, cultures, and infrastructure of a university, it becomes difficult to situate OER as sustainable in itself. It is the active contribution of all stakeholders that enables an OER adoption program to thrive at the institutional level, because programs, like OER, must be designed and iterated to fit the contexts of a specific university.

\section{The K-State OAER Model}

The K-State Open/Alternative Textbook Initiative (OATI) is now in its fourth year. Spearheaded by faculty members from Mathematics, Food, Nutrition, Dietetics and Health, and the Libraries, the design of KState's initiative recognizes that a lack of financial reward, release time, and university support discourages faculty from implementing open or alternative resources to replace textbooks within their courses. Mindful of grant-awarding initiatives like those at Temple University, the University of Massachusetts at Amherst, and other institutions where faculty are provided stipends to adopt and adapt low- or no-cost replacements for traditional textbooks, K-State strategists anticipated that their faculty may be reluctant to adopt, develop, and maintain open or alternative resources without the promise of recurring monetary incentives (Lindshield \& Adhikari, 2013). Thus, a \$10 open/alternative textbook fee was proposed and recently approved for each student who enrolls in a course taught using what they refer to as open/alternative educational resources (OAER) - a term developed to balance their aspirational pursuit of "open" specifically with the practical implementation of textbook alternatives in general. By not requiring all resources to be truly open, faculty who are unfamiliar with OER could come to learn about open resources and licensing at their own pace. Recognizing the need for additional value adds when instating a student fee, the faculty members behind the initiative have maintained a commitment to customizing and innovating course materials in in favor of student expectations and interests. The use of open-licensed, library-purchased, and instructor-provided content in producing engaging alternatives to typical textbooks is thus prioritized by the initiative. This model standardizes and reduces textbook costs for students while ensuring recurring funding to academic departments and the sustained support of faculty members as they develop and implement OAER within their courses. While details about the K-State Open/Alternative Textbook Initiative (KOATI) are available elsewhere (Delimont, Turtle, Bennett, Adhikari, \& Lindshield, 2016), the factors that led to this initiative's inception and sustained growth are more thoroughly outlined below.

\section{The Origin of KOATI}

The KOATI at K-State, a public research university supporting an undergraduate and graduate population of roughly 25,000 across nine colleges, may have originated with faculty, but financial support from KState's student government is what launched the program's university-wide scope. In late December 2012, organizers submitted a \$50,000 Student-Centered Tuition Enhancement (SCTE) proposal in an effort to fund grants for faculty who would replace their course textbook(s) with OAER. Because SCTEs are funded by tuition dollars and are intended to "create visible and positive change to the university" (Student Governing Association, n.d., para. 2), two suspected advantages for this proposal were the 
interdepartmental nature of the collaboration backing the KOATI and an offer of an additional $\$ 10,000$ of financial support from the K-State Libraries if a \$50,000 ask was awarded through SCTE. This SCTE proposal was accepted in April, and a call for OAER proposals was drafted and distributed to faculty. Table 1 summarizes annual initiative activities.

Table 1

Annual Initiative Activities

\begin{tabular}{|c|c|}
\hline \multicolumn{2}{|r|}{ Spring } \\
\hline Early April & Call for OAER grant proposals \\
\hline Mid May & Announce faculty OAER grant awards \\
\hline Early July & Awardees receive first half of their grant funds \\
\hline Early November & $\begin{array}{l}\text { Distribute second half of funds if faculty meet approved } \\
\text { expectations/outcomes and are teaching with resource instead of textbook } \\
\text { during Fall Semester }\end{array}$ \\
\hline \multicolumn{2}{|r|}{ Fall } \\
\hline Late September & Call for OAER grant proposals \\
\hline Early November & $\begin{array}{l}\text { Initiative faculty communicated with and/or met individually with } \\
\text { awardees to discuss their progress and plans for completing and/or } \\
\text { teaching with OAER }\end{array}$ \\
\hline Early December & Announce faculty OAER grant awards \\
\hline Early January & Awardees receive first half of their grant funds \\
\hline Early February & $\begin{array}{l}\text { Distribute second half of funds if faculty meet approved } \\
\text { expectations/outcomes and are teaching with resource instead of textbook } \\
\text { during Spring Semester }\end{array}$ \\
\hline Late April & $\begin{array}{l}\text { Awardees upload resources to LMS, allowing all awardees to access } \\
\text { resources prior to meeting and discussing their experiences from } \\
\text { participating in the initiative }\end{array}$ \\
\hline Summer & $\begin{array}{l}\text { Initiative faculty communicate with and/or meet individually with } \\
\text { awardees to discuss their progress and plans for completing and/or } \\
\text { teaching with OAER }\end{array}$ \\
\hline
\end{tabular}

Since SCTE funding was likely a one-time award, KOATI organizers sought representation and input from across the university to raise awareness and promote the importance of OAER to K-State moving forward. Given that the Student Governing Association (SGA) provided most of the initiative's funding, KOATI organizers involved students in the review of faculty proposals. Two to three students served on panels 
during the first two years of funding. In addition to these students, invitations to serve on the evaluation panel were also extended to the staff of the Teaching and Learning Center and to the Office of Vice Provost for Undergraduate Studies. A representative from each served on a panel during the first year. Awards went to 12 out of the 14 applicants, with $\$ 60,000$ committed to funding their OAER projects during the first year of the program. All 12 faculty members proved successful in creating, adapting, and/or adopting OAER to use in their courses and received full financial compensation. Resulting OAER took a variety of forms including adapted OpenStax resources, interactive course modules within the K-State learning management system (LMS), instructional videos or website media, and iBooks-based alternative texts.

\section{Iterating KOATI}

After the first year, the wording in the 2013 call for SCTE applications had been revised to discourage repeat awards but few alternatives existed through which the initiative might secure funding. The K-State Libraries again pledged $\$ 10,000$ in funding and a smaller $\$ 30,000$ SCTE application was submitted in December 2013. The more modest proposal was accepted, and the KOATI began implementing the same schedule outlined in Table 1 for the program's second year. In summer 2014, the K-State president and provost requested a meeting with organizers to learn more about the KOATI and expressed interest in supporting and potentially expanding the initiative based on its success and estimated returns on investment. A proposal was developed for central administration by KOATI leaders that described an approach for scaling up the adoption of OAER with the goal being that OAER would replace commercial textbooks in $75 \%$ of freshmen and sophomore courses.

Just before the review of OAER applications for Fall 2014, a pair of 2015-2016 student body president and vice president candidates contacted KOATI organizers and were interested in learning more about the program and potentially including it as a part of their collective SGA platform. The candidates served as student representatives on the Fall 2014 evaluation panel and were later elected on a platform that included the KOATI. During the Fall Semester, word circulated that funding for the KOATI would be provided by the central administration, so organizers did not submit an SCTE application. At the same time, two initiative leaders, who were also faculty senators, sought an endorsement from the governing body. Faculty senate approved the endorsement in December 2014, and it was later learned that the president would not have provided funding to the initiative without this endorsement. The resulting $\$ 50,000$ received from central administration was in line with the initial award granted under SCTE; however, this new funding source did not honor the additional financing that the committee requested to increase the scale of the initiative. The endorsed proposal is provided in the Appendix.

In addition to the initiative leaders already serving, the panel reviewing OAER proposals was revised in spring 2015 to include a previous awardee, as well as an accessibility specialist. The former was appointed to offer additional perspectives as a member of K-State's OAER community. The latter came about as conversations about accessibility and universal design became more prevalent around the initiative and as specific questions about student accessibility were integrated into OAER applications. The inclusion of a previous awardee and an accessibility specialist thus broadened the understanding of stakes and opportunities at K-State and strategically situated the initiative as complementary to institutional and academic goals. 
Under the urging and support of the student body president and vice president, the K-State Division of Communications and Marketing produced a promotional video (https://www.youtube.com/watch?v=nHjsyW2RJBI) to build awareness of the KOATI. Around this time, the president proposed transitioning the initiative from an institution-to a donor-funded model, and another video was envisioned targeting donors. Although this second video was created, it was never circulated due to a sequence of events, including slow funding model approval, university budget cuts, fewer-than-expected OAER applications (Table 2), and the president's departure during the Spring 2016 Semester. These setbacks along with university community feedback led to discussions within the initiative about the idea of a student course fee-a prospective approach that one member of the initiative had investigated previously (Lindshield \& Adhikari, 2013).

Initiative leaders engaged the student body president and vice president about their thoughts on a course fee to help spur greater adoption of OAER and provide a more sustainable and stable funding source for the program. Both student leaders supported the idea, and they arranged a meeting between with KOATI organizers and the president to discuss the prospect. A $\$ 10$ per-course fee was proposed during this meeting, of which $\$ 9$ would be returned to any academic department offering an OAER course and $\$ 1$ invested into the KOATI. In addition to the fee, the initiative was one of three presentation topics at the KState Foundation Board of Directors Meeting, which includes the university's largest donors. If a combination of donor funds for initial instructor awards could be coupled with a student course fee, the funding structure could allow for a far more sustainable implementation of OAER at a larger scale.

An application for the fee was submitted to the provost shortly before the president announced he was leaving the university. The Tuition Strategies Committee reviewed the proposal, and the request could have also gone before the Board of Regents for approval if the proposed fee were a more typical college or divisional ask. Fees applications only go to the regents if they are expected to generate a certain dollar amount, and year-one estimates for the Open/Alternative Textbook Course (OATC) fee fell well below that threshold. In a meeting with an KOATI leader who had recently been appointed Faculty Senate President, the provost offered official approval to implement the fee in Fall Semester 2016.

\section{Outcomes}

During the 2014-2015 and 2015-2016 academic years, an estimated 17,963 students enrolled in courses being taught with OAER and saved approximately $\$ 1.61$ million. These totals were calculated using the actual cost of textbooks that were priced below $\$ 100$ and capping estimated costs for materials at $\$ 100$ when they exceeded that amount, which sets the average cost savings per student per course at $\$ 89.63$ from 2014 to 2016. This corrected calculation gives a more conservative estimate of savings that could account for the common price reduction strategies that students employ instead of purchasing a new textbook: renting, buying used, purchasing access codes for e-textbooks, and so on. During the 2015-2016 academic year alone, an estimated 10,941 students enrolled in courses using OAER and found savings around $\$ 921,000$. 
Given the university's financial investment in OAER courses was under $\$ 150,000$, the annual return on investment was 6 times greater in terms of student savings. Assuming that these courses continue to use OAER as other courses adopt OAER, this rate will only grow over time.

If, from the beginning, a $\$ 10$ course fee were imposed on the 17,963 students who paid nothing for OAER in the first few years of the program, $\$ 179,630$ worth of funding could have resulted with $\$ 161,667$ going back to the academic departments and \$17,963 supporting the KOATI. Rather than save an estimated \$1.6 million, students would have saved a little under $\$ 1.4$ million (an $11 \%$ difference). While it is still unknown whether the course fee will provide enough financial incentive for departments to replace course textbooks with OAER, a course with 100 enrolled students will generate $\$ 900$ for the department every time it offers that course. A significant change here is that funding to develop OAER has transitioned from one-time to recurring due to the student course fee and is likely to incentivize those who administrate high-enrollment and -demand courses.

Table 2

Number of Applications, Awards, and Funds Committed During the 3.5 Years of the Initiative

\begin{tabular}{|c|c|c|c|}
\hline Semester & \# of Applications & \# of Awards & Funds Committed \\
\hline Spring 13 & 11 & 9 & $\$ 46,060$ \\
\hline Fall 13 & 3 & 3 & $\$ 13,940$ \\
\hline Spring 14 & 11 & 7 & $\$ 31,250$ \\
\hline Fall 14 & 9 & 6 & $\$ 27,000$ \\
\hline Spring 15 & 11 & 7 & $\$ 31,750$ \\
\hline Fall 15 & 5 & 4 & $\$ 18,000$ \\
\hline Spring 16 & 4 & 4 & $\$ 15,500$ \\
\hline Totals & $\mathbf{5 4}$ & $\mathbf{4 0}$ & $\mathbf{\$ 1 8 3 , 5 0 0}$ \\
\hline
\end{tabular}

The decline in faculty applications to KOATI over time (Table 2) might indicate that those instructors who were most ready to make a change had applied and received funding early in the initiative's life. Departmental support and responsibilities may also have weighed in on an individual's ability to participate, however. Because the student course fee will likely increase buy-in from departments, especially those offering courses frequently and/or with high enrollments, instructors may find more encouragement and resources from departmental leadership. With $90 \%$ of the revenue from the fee going to the department that offers an OATC, there is a strong incentive for a department to support its faculty in moving from commercial texts to OAER when the same set of course materials are often used by more than one instructor and decisions about which course materials are required often reside with the greater department. As the members of academic departments find support in the reliable resources and funding provided by the 
KOATI, the sustainability of the K-State model is assured through growth in faculty participation and public awareness: the more students know about OAER, the more like they are to enroll in an OATC.

One measure to increase awareness among students has already been implemented in the form of interactive icons that distinguish a course with commercial texts from an OATC in the course catalog and online registration systems. The gray textbook icon (Figure 1) is hyperlinked to a bookstore web page that provides information about the course materials that are recommended and/or required for purchase. The purple OAER icon (Figure 1) exists as a counterpart to the traditional textbook icon and links to a page on the KOATI website that provides information about why a textbook purchase is not required for the course as well as pertinent details about the OATC fee. In addition to increasing the visibility of OAER for K-State students, this communication measure was developed as a response to student questions and concerns to instructors about there not being a required textbook to purchase in OAER courses. Simply, textbooks and other commercial course materials are so ingrained in popular conceptions of college life that students continue to express doubt in the face of an institutionalized implementation of low- and no-cost alternatives. The outcome associated with these icons-breaking down cultural barriers through public awareness campaigns - may be less conventional than considerations of the savings brought forth by typical textbook replacement initiatives, but it seems a valuable one nonetheless.
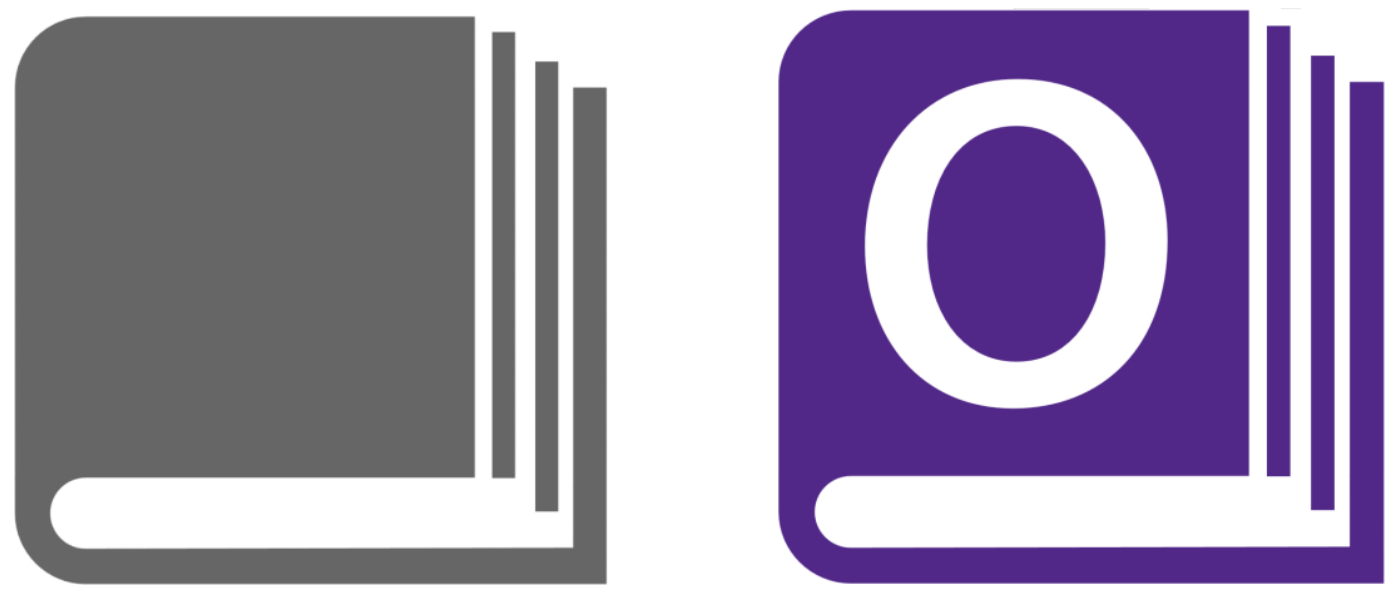

Figure 1. Regular Book Icon (left) and Open/Alternative Textbook Icon (right).

\section{The Outcomes of " $O$ " in KOATI}

Some may wonder just how open an initiative is when it endorses OER and varyingly closed, alternative resources. Awardees whose resources were not technically OER, or were in active development, were contacted in November 2016 to determine two things: their interest in making their resources open and view on openness in general. Table 3 summarizes the different types of resources that have been funded so far. Despite KOATI's support of open and non-open textbook alternatives alike, OER are the most common type of resource being utilized. One faculty member who has received two awards that resulted in the two 
publicly available website resources has expressed interest in making the websites' content open through a Creative Commons licenses rather than copyrighted. Six of the 11 awardees who have authored document resources indicated that they were in the process of making them open or interested in making them open. One awardee did not think their resources were ready to be made open yet, while two others noted that their resources could not be made open because they contained copyrighted content. Among those with iBook resources, one awardee, who has received two awards, expressed interest in moving them to a different platform in order to make them open. The other iBook author indicated a preference to focus on K-State students rather than making it open. The LMS module resources typically use copyrighted resources and thus are not openly available. For instance, one OAER has used library resources heavily in order to access library-subscribed music licenses.

Table 3

Number (Percentage) of OAER Category

\begin{tabular}{|c|c|c|c|c|c|}
\hline OER & Documents & $\begin{array}{c}\text { Under } \\
\text { Development }\end{array}$ & iBook & $\begin{array}{c}\text { LMS } \\
\text { Modules }\end{array}$ & Website \\
\hline $13(32.5 \%)$ & $11(27.5 \%)$ & $6(15 \%)$ & $4(10 \%)$ & $4(10 \%)$ & $2(5 \%)$ \\
\hline
\end{tabular}

To answer the question posed at the beginning of this section, a majority of the resources are OER (32.5\%), publicly available (5\%), and being made open or their authors are exploring the idea (17.5\%). It is important to note that many of the resources in development (15\%) will also be OER eventually. The time needed for faculty to reach a point where they are comfortable making resources open is not something that should be discounted or overlooked. Also, time and encouragement were needed for faculty to understand the value in making resources open. Some awardees that expressed new interest in making their resources open are those who did not regard it as a priority or would not have considered the pursuit when they received their award.

\section{Early Outcomes of Fee Implementation}

For the first year of fee implementation, the decision was made to focus on courses and instructors that had previously received an award from or were involved in the initiative. Courses that used an approved OAER and did not require other course materials to be purchased by students were fee-eligible. Using this criterion, \$43,110 was assessed to students in 19 Fall 2016 courses. In October 2016, fee funds were disbursed to departments teaching the courses. Nine awardees (excluding one awardee who stopped using the resource after one year, another awardee who left the university, and another who passed away), whose courses were not fee-eligible for the fall, were contacted about their Spring Semester plans. One awardee removed a required supplementary physical published book that the awardee had written and another faculty member, whose teaching assignment had changed to a different course, planned to modify and revise the alternative document for the new course to make it fee-eligible. Such activities are significant in reducing student expenses. 
The first application deadline after the fee was announced to campus was in November 2016, the initiative has since received 14 KOATI award and 19 fee applications (36 total applications). The fee applications are for OAER that are already being used and could make a course fee-eligible. It is worth noting that 17 of the fee applications were from one college where the dean has actively encouraged department heads and faculty to embrace the opportunity and submit award and fee applications. While most of the fee applications have been for alternative resources that are LMS modules, it may be that interest in making these open will arise over time as it has for other awardees who have employed like resources. Based on this college, targeting college administrator meetings that include department heads, deans, and associate deans as a means to get the message out about and gain support for KOATI might be an effective approach. In addition, having one college "buy in" may assist in marketing them as a model for other colleges to emulate.

\section{Recommendations and Conclusions about OAER}

K-State's model for replacing commercial textbooks with OAER at a low cost is one that inevitably complements the culture its institution. What began as a small, interdepartmental effort to adopt, adapt, and promote OAER across disciplinary lines for the betterment of students has since instigated a growing awareness and broad buy-in from university leadership-from student government to central administration-and resulted in the approval of a sustainable funding structure for the initiative. For public, four-year universities many common hurdles may exist when implementing OER adoption at the institutional level. By keeping barriers of participation low, offering consistent support of faculty creation and sharing, providing ample opportunities to collaborate and network across departmental lines, and promoting and rewarding the efforts of individuals as part of a broader community, the authors of this note find K-State's sustainability to be directly tied to its success in facilitating participatory cultures.

Through strategic partnering, not only does the K-State model show that faculty, staff, and students may start enacting change without the involvement of upper administration, it positions doing so as the most expedient means of launching an initiative and gathering data. When an experimental university-wide initiative develops independently of central leadership, the lower stakes minimize impact to the greater institution in the event of a failure, and the lack of institutional oversight allows for a greater degree of trial and error to occur when fashioning the goals and practices that necessarily undergird a sustainable movement. All activities associated with an initiative like the one at K-State require time and resource investments for which an individual or group might more commonly receive some sort of compensation. Whether individuals are organizing, reviewing, contributing, or maintaining the proliferation of OER and OAER at a university, varying degrees of volunteerism must be garnered. Simply, there would be no scalable way for all those involved with the development, modification, and distribution of OAER to break even on their investments. Comprehending this potential limitation, however, K-State was able to find more immediate scale and impact by instituting low-cost OAER instead of uncompromisingly pursuing OER.

As a means of iteratively garnering faculty knowledge of and interest in OER, OAER seem like a significant step forward. It is difficult to dispute that sheer openness is an ideal quality for educational resources to harbor in an age of high-priced textbooks. Not-necessarily-open textbook alternatives, however, may 
facilitate arguably greater immediate adoption from any instructor because s/he is capable of both leveraging paid-for university, and copyrighted resources when developing content and devoting more time and attention to designing materials around their students' needs. For these reasons, initiatives that start with a push for low-cost yet innovative alternative resources, in particular, may meaningfully prompt a general interest in OER. As the OATI matures and awareness of OER grows at K-State, it seems reasonable to assume that course materials will become increasingly open as the alteration and sharing of educational resources continues to circulate culturally.

\section{References}

Allen, I. E., \& Seaman, J. (2016). Opening the Textbook: Educational resources in US higher education, 2015-16. Babson Survey Research Group. Retrieved from http://www.onlinelearningsurvey.com/reports/openingthetextbook2016.pdf

Andrade, A., Ehlers, U.D., Caine, A., Carneiro, R., Conole, G., Kairamo, A.K. . . Holmberg, C. (2011). Beyond OER: Shifting focus from resources to practices. Retrieved from https://oerknowledgecloud.org/sites/oerknowledgecloud.org/files/OPAL2011.pdf

Bliss, T., Hilton, J., III, Wiley, D., \& Thanos, K. (2013). The cost and quality of online open textbooks: Perceptions of community college faculty and students. First Monday, 18(1). doi:http://dx.doi.org/10.5210/fm.v18i1.3972

Buczynski, J. A. (2007). Faculty begin to replace textbooks with "freely" accessible online resources. Internet Reference Services Quarterly, 11(4), 169-179. doi: http://dx.doi.org/10.1300/j136v11no4_11

Bureau of Labor and Statistics. (2016, August 30). College tuition and fees increase 63 percent since January 2006 [Web blog]. The Economics Daily. Retrieved from http://www.bls.gov/opub/ted/2016/college-tuition-and-fees-increase-63-percent-since-january2006.htm

Delimont, N., Turtle, E., Bennett, A., Adhikari, K., \& Lindshield, B. (2016). University students and faculty have positive perceptions of open/ alternative resources and their utilization in a textbook replacement initiative. Research In Learning Technology, 24. doi:http://dx.doi.org/10.3402/rlt.v24.29920

Downes, S. (2007). Models for sustainable open educational resources. The Interdisciplinary Journal of Knowledge and Learning Objects, 3, 29-44. Retrieved from http://www.ijello.org/Volume3/IJKLOv3po29-044Downes.pdf

Everard, A., \& Pierre, K. S. (2014). A case for student adoption of open textbooks. Journal of the Academy of Business Education, 15, 66-76. Retrieved from http://connection.ebscohost.com/c/articles/101788630/case-student-adoption-open-textbooks 
Friesen, N. (2009). Open educational resources: New possibilities for change and sustainability. The International Review of Research in Open and Distributed Learning, 1O(5). Retrieved from http://www.irrodl.org/index.php/irrodl/article/view/664/1388

Hilton III, J. L., Lutz, N., \& Wiley, D. (2012). Examining the reuse of open textbooks. The International Review of Research in Open and Distributed Learning, 13(2), 45-58. Retrieved from http://www.irrodl.org/index.php/irrodl/article/view/1137

Hilton III, J. L., Robinson, T. J., Wiley, D., \& Ackerman, J. D. (2014). Cost-savings achieved in two semesters through the adoption of open educational resources. The International Review of Research in Open and Distributed Learning, 15(2). Retrieved from http://www.irrodl.org/index.php/irrodl/article/view/1700/2833

Hilton III, J.L., \& Wiley, D. (2010). A sustainable future for open textbooks? The Flat World Knowledge story. First Monday, 15(8). Retrieved from http://www.uic.edu/htbin/cgiwrap/bin/ojs/index.php/fm/article/view/2800/2578

Hilton III, J., \& Wiley, D. (2011). Open access textbooks and financial sustainability: A case study on Flat World Knowledge. The International Review Of Research In Open And Distributed Learning, 12(5), 18-26. doi: http://dx.doi.org/10.19173/irrodl.v12i5.96o

Howard, J. (2012, November 3). Flat world knowledge to drop free access to textbooks. Retrieved September 4, 2016, from: http://www.chronicle.com/blogs/wiredcampus/flat-world-knowledgeto-drop-free-access-totextbooks/40780?utm source=feedburner\&utm medium=feed\&utm campaign $=$ Feed $\% 3$ A+chronicle\%2Fwiredcampus+(The+Chronicle\%3A+Wired+Campus)

Jenkins, H., Purushotma, R., Clinton, K., Weigel, M., \& Robinson, A. J. (2006). Confronting the challenges of participatory culture: Media education for the $21^{\text {st }}$ century. Chicago: The MacArthur Foundation. Retrieved from http://www.newmedialiteracies.org/wpcontent/uploads/pdfs/NMLWhitePaper.pdf

Lederman, D. (2012, November 5). Fleeing from 'free' [Web blog]. Retrieved from https://www.insidehighered.com/news/2012/11/05/flat-worlds-shift-gears-and-what-it-meansopen-textbook-publishing

Lindshield, B.L. \& Adhikari, K. (2013). Campus and online U.S. college students' attitudes toward an open educational resource course fee. International Journal of Higher Education, 2(4), 42-51. 2013. doi:10.5430/ijhe.v2n4p42

McKerlich, R., Ives, C., \& McGreal, R. (2013). Measuring use and creation of open educational resources in higher education. International Review of Research in Open and Distance Learning, 14(4), 90-102. Retrieved from http://www.irrodl.org/index.php/irrodl/article/view/1573 
Paulsen, M. B., \& St. John, E. P. (2002). Social class and college costs: Examining the financial nexus between college choice and persistence. The Journal of Higher Education, 73(2), 189-236. doi:http://dx.doi.org/10.1353/jhe.2002.0023

Provasnik, S., \& Planty, M. (2008). Community colleges: Special supplement to the condition of education 2008. Statistical Analysis Report. NCES 2008-033.

National Center for Education Statistics. Retrieved from http://nces.ed.gov/pubsearch/pubsinfo.asp?pubid=2008033

Student Governing Association. (n.d.). SGA documents. Kansas State University. Retrieved from http://www.k-state.edu/sga/documents/

UNESCO. (2002). Forum on the impact of open courseware for higher education in developing countries: Final report. Retrieved from http://unesdoc.unesco.org/images/o012/001285/128515e.pdf

Wiley, D.A. (2000). Connecting learning objects to instructional design theory: A definition, a metaphor, and a taxonomy. In D.A. Wiley (Ed.), The instructional use of learning objects: Online version. Retrieved from http://reusability.org/read/chapters/wiley.doc

Wiley, D., Bliss, T. J., \& McEwen, M. (2014). Open educational resources: A review of the literature. In J.M. Spector, M.D. Merrill, J. Elen, \& M.J. Bishop (Eds.), Handbook of research on educational communications and technology (pp. 781-789). New York: Springer.

Doi:http://dx.doi.org/10.1007/978-1-4614-3185-5_63

William and Flora Hewlett Foundation. (2013). Open educational resources:Breaking the lockbox on education [White paper]. Retrieved from http://www.hewlett.org/wpcontent/uploads/2016/08/OER\%20White\%20Paper\%20Nov\%2022\%202013\%20Final_o.pdf 


\section{Appendix}

\section{Open/Alternative Textbook Proposal}

\section{Overview}

The College Board estimates that an average student spends over \$1ooo per year on textbooks. With over 19,ooo undergraduates, that would be a total of around \$2O million per year spent by our students on textbooks. By moving away from purchased textbooks, we can recover part of this money, reducing costs to our students while increasing funds available to meet the goals of K-State 2025.

With support from the student government and K-State Libraries, we have run the Open/Alternative Textbook program for the past two years. This program has provided grants, typically of around $\$ 5000$, to faculty who wish to convert their class to use free materials. This has involved everything from updating a syllabus to use existing online materials in place of a purchased textbook, designing supplemental materials to adapt existing online materials to the needs of a specific course, developing a completely new online text, or moving from a textbook entirely to using video or other modern resources. The program has been very successful in saving students significant amounts of money on textbooks in the affected classes, with $\$ 96,000$ in one-time awards leading to annual savings in the range of $\$ 800,000$ to $\$ 1$ million. Furthermore, initial results are that using materials that are more precisely aligned with the course leads to increased student use and increased student learning. This is a successful program and should be rapidly expanded. There are several issues that can and should be addressed in this expansion.

- We have only been able to address about 20 classes over three semesters of funding. While we have targeted primarily large-enrollment classes, the amount of total funding needs to be significantly increased for students to know most of their (at least low-level) classes will not require costly textbooks.

- Because funding from the student government comes at inconvenient times, our advertising of the availability of funds has been limited to a short window. While conversations with faculty show many are interested in moving to a more affordable model for textbooks, they need to have time to think through the issues and plan before submitting a proposal, which is not possible given the current funding window.

- Right now we only need to fund new developments. But just as textbooks come out with new editions every 4 years or so, running a course with an open/alternative textbook requires maintenance. In a few years we will need to be funding proposals for updating materials as required due to changes in course content and technology.

\section{Proposed Plan of Action}


1. Funding for the Open/Alternative Textbook Initiative should become a responsibility of central administration, rather than depending on grants from student government. With guaranteed funding, a grant process could be advertised and run on a set schedule, improving faculty response. While the office of the vice provost for undergraduate studies seems a likely home for the initiative, the details of administration can be worked out later.

2. Grant funding should increase from the current average of $\$ \mathbf{3 6}, 000$ per semester to $\$ 80,000$ per semester by spring 15, and then to $\$ 160,000$ per semester in FY 16 and $\$ 240,000$ per semester in FY 17. This will provide adequate amounts for about 120 courses to change, figuring roughly one summer month of pay per course. For FY 18 it will be reasonable to look at providing maintenance grants in addition to funding new developments. That seems a reasonable time to look at progress and decide on what levels of future funding are appropriate.

3. Workshops and professional development opportunities to support changing to open/alternative textbooks should be created, including paid mentoring. Faculty are more likely to think of changing to open/alternative textbooks when they can see successful models. Now that we have a cadre of early adopters who have built or adapted materials for their own classes, we should leverage their experience to help other faculty who are interested in making changes but aren't sure where to begin or how much work it will be. In addition to funding the workshops, we should also be funding faculty who have completed projects to serve as mentors to less experienced faculty beginning the process. An initial stipend of $\$ 1000$ per project seems reasonable.

4. The university should openly move toward a goal of significantly reducing studentpurchased textbooks. To be truly successful, we need to move from saving students money in selected courses, as worthwhile as that is, to allowing students and their families to know they can budget significantly less for books. This requires that we move from a case where open/alternative textbooks are a possibility to where they are the norm. This requires that the campus have a conversation about the issue. The administration and faculty senate can work together to spark such a conversation and eventually adopt such a goal.

5. Donor funding should be sought to support Open/Alternative Textbook Initiative. Significant donor support should be found for the goal of replacing purchased textbooks, particularly in the current climate when college and textbook costs are featured in the news. Donors like to donate money that directly affects students. Our experience shows that money donated toward replacing textbooks pays off in student savings in large multiples. In addition, we can provide donor recognition in the online materials.

\section{Budget}

The budget will scale up to be on the order of $\$ 400,000$ by fiscal 2017 . This includes $\$ 300,000$ in direct grants for FY 17. If every proposal has a paid mentor, that would add an additional $\$ 60-70,000$, 
but of course not every project is likely to need or want a mentor. An additional amount needs to be provided for running workshops and other professional development opportunities, leading to the rough estimate of $\$ 400,000$ per year. The plan calls for the budget to scale up over time so we will not reach that level immediately. Given that the current pilot program is already saving students on the order of $\$ 800,000$ to $\$ 1$ million a year, this seems a reasonable investment, particularly if some funding can be raised from donations.

\section{Outcomes}

\section{Primary Outcome}

- By Fall 2018, over 75\% of student credit hours in the first year of college will not require purchasing a textbook. There are approximated 200 lower-level classes that use a textbook currently on campus. While some faculty will not change, others have already switched to open/alternative materials. Targeting the larger classes, we will need about 75-10o classes to switch to meet this goal. This is a stretch, but with both improved funding and increased campus acceptance of the need to consider open/alternative textbooks, it seems possible. We will of course also try to encourage and support faculty in higher-level classes in using open/alternative textbooks as appropriate.

\section{Secondary Outcomes}

- K-State will become more affordable. By decreasing the overall amount students pay, we will become more affordable for both in-state and out-of-state students. Since financial issues are the primary barrier to student enrollment and are one of the two main issues in retention, this should directly improve our enrollment management efforts, our freshman-sophomore retention rate, and our six-year graduation rate.

- K-State students will learn more. Giving faculty a month of summer support to adapt or develop course materials will improve the learning experience for students. Open/Alternative materials offer the ability to more closely integrate the materials and the course than a prepackaged textbook. They also can be updated much more quickly and easily to adapt to changing situations. Students learning will improve with the appropriate use of these materials.

- We will become part of the national conversation about top colleges. Making and keeping a plan to significantly reduce purchased textbooks will be a signature accomplishment that will draw national attention to K-State. Such stature will improve our ability to draw students from across the country and the world. It will also make it easier to attract top-tier talent in pursuit of the goals of K-State 2025 . 
Cultivating Textbook Alternatives From the Ground Up Lashley, Cummings-Sauls, Bennett, and Lindshield

Athabasca

University

(c) 